\title{
A Novel Interleaving Control Scheme for Boost Converters Operating in Critical Conduction Mode
}

\author{
$\mathrm{Xu}$ Yang*, Yanping Ying*, and Wenjie Chen ${ }^{\dagger}$ \\ ${ }^{\dagger *}$ State Key Lab. of Electrical Insulation and Power Equipment, Xi'an Jiaotong University, Xi'an, China
}

\begin{abstract}
Interleaving techniques are widely used to reduce input/output ripples and to increase the power capacity of boost converters operating in critical conduction mode. Two types of phase-shift control schemes are studied in this paper, the turn-on time shifting method and the turn-off time shifting method. It is found that although the turn-off time shifting method exhibits better performance, it suffers from sub-harmonic oscillations at high input voltages. To solve this problem, an intensive quantitative analysis of the sub-harmonic oscillation phenomenon is made in this paper. Based upon that, a novel modified turn off time shifting control scheme for interleaved boost converters operating in critical conduction mode is proposed. An important advantage of this scheme is that both the master phase and the slave phase can operate stably in critical conduction mode without any oscillations in the full input voltage range. This method is implemented with a FPGA based digital PWM control platform, and tests were carried out on a two-phase interleaved boost PFC converter prototype. Experimental results demonstrated the feasibility and performance of the proposed phase-shift control scheme.
\end{abstract}

Key Words: Critical conduction mode, Interleaving, Phase shift, Sub-harmonic oscillation

\section{INTRODUCTION}

Boost converters operating in critical conduction mode (CRM) can achieve zero current switching (ZCS) for the diode and eliminate its reverse recovery loss, which enables the application of a low cost silicon PiN diode while still keeping switching losses low. However, in this operation mode, the switching frequency is variable and thus the current/voltage ripple of converters with CRM is higher than it is in converters with continuous conduction mode (CCM). This is generally undesirable for high power and power factor correction applications [1]-[3]. Therefore, in many high power applications, multiple phase boost converters are often adopted in order to increase the power capacity and interleaving operation is used to cancel the current ripple and reduce the volume of the input EMI filter. Meanwhile, the input/output current/voltage ripple can still be minimized without sacrificing efficiency [4]-[6].

It is well known that, it is not difficult to achieve interleaving control for converters operating at a constant frequency. However, it is difficult to generate gate signals for converters operating in CRM. Traditionally, there are two types of interleaving control schemes, the turn-on time shifting method and the turn-off time shifting method [7]-[10]. With the turnon time shifting method, a boost converter operated in the slave phase may turn on before the inductor current reaches zero, and it may lose ZCS for the diode. Thus the turn-off

Manuscript received Jan. 4, 2010; revised Feb. 7, 2010

$\dagger$ Corresponding Author: cwj@mail.xjtu.edu.cn

Tel: +86-29-82665223, Xi' an Jiaotong University

* State Key Lab. of Electrical Insulation and Power Equipment, Xi'an

Jiaotong University, China time shifting method appears to be a better choice since both the master phase and the slave phase can be worked with CRM operation which guarantees ZCS operation for the diode in any case. However, a so-called sub-harmonic oscillation phenomenon occurs at high line voltages for this operating mode.

One solution is to add a transformer in order to increase the output voltage. However, the objectives of high power density and low cost will not be accomplished. For this reason and, in order to maintain the high efficiency of the converter, a complete analysis of the sub-harmonic oscillation phenomenon is made in this paper. Then a novel modified turn off time phase-shift interleaving control scheme is proposed. A distinguished feature of the proposed scheme is that the slave phase can operate in the critical conduction mode and the phase-shift is nearly $360^{\circ} / N$. ( $N$ is the number of phases in parallel.)

In addition, since a phase-shift control scheme is usually realized by analog circuits, the solution for an ideal phaseshift will inevitably lead to a complex analog control circuit. In this paper, a digital PWM control circuit based on a FPGA is used to implement the control scheme, which greatly simplifies the design process. The experimental results of a two-phase interleaved CRM boost PFC are presented to verify the feasibility and performance of the novel phase-shift control scheme.

This paper is organized as follows: first, an evaluation of existing control schemes is introduced for interleaved boost converters operating in critical conduction mode in section II. In section III, an analysis of the sub-harmonic oscillation 
problems in turn off time shifting control is made in detail. The derivation of the proposed control scheme for phase-shift is given in section IV. Finally, in section V, the proposed control scheme is implemented and verified in a boost PFC rectifier.

\section{EVALUATION OF EXISTING CONTROL SCHEMES}

The system configuration of a two-phase interleaved CRM boost PFC converter and its key waveforms are shown in Fig. 1 . The switch is turned on when the inductor current reaches zero. The turn-on time is controlled to be constant. Because of the high current/voltage ripple, interleaving operation is usually used to damp the current and voltage stress.

In this section, two types of existing interleaving control schemes are discussed. The interleaving control scheme shown in Fig. 2 shifts the turn-on signal to achieve interleaving operation. The scheme shown in Fig. 3 shifts the turn-off signal and the slave phase turns on when the inductor current becomes zero. For converters with a constant frequency, it is easy to determine the phase-shift interval. For a twophase boost converter with CRM operation, the operation is varying. The interleaving signal can be generated from the turn-on signal $P_{1}$ or the turn-off signal $P_{2}$ by shifting these signals with $T_{s} / 2$ or $T_{s}^{\prime} / 2$. The master phase is turned on by zero current detectors and turned off by a variable on-time controller. We assume that the difference between the two adjacent operation periods can be omitted. As a result, we can use the previous operation period to determine the present shift period. For high frequency operation, this assumption is feasible.

\section{A. Type I Phase shift method}

As shown in Fig. 2, the slave phase is turned on by shifting the turn-on signal P1, which is generated from the master phase and always lagging the master phase by $180^{\circ}$. The turnon time of the master phase and the slave phase are equal.

With this phase-shift method, the slave phase may work in CCM or DCM mode, since the turn-on signal may not occur while the inductor current of the slave phase drops to zero.

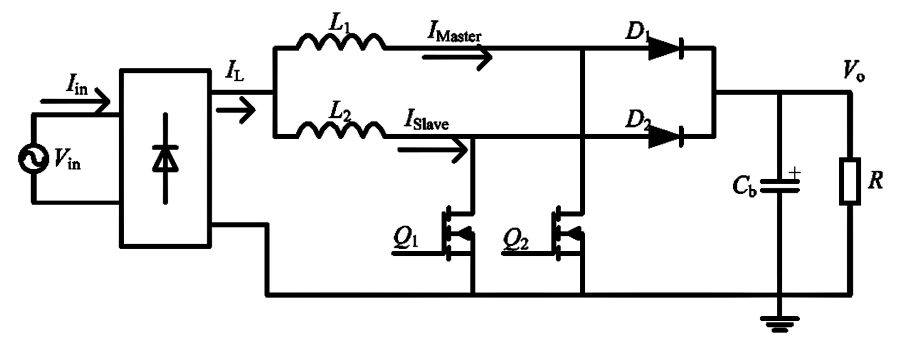

(a) System configuration

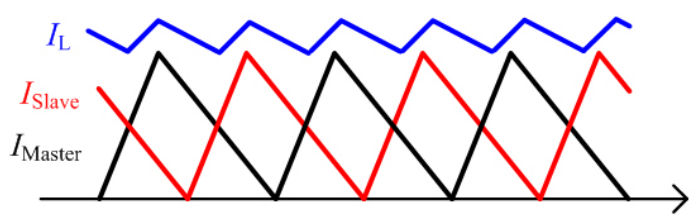

(b) Key waveforms

Fig. 1. System diagram and its key waveforms of a two-phase interleaved CRM boost PFC.

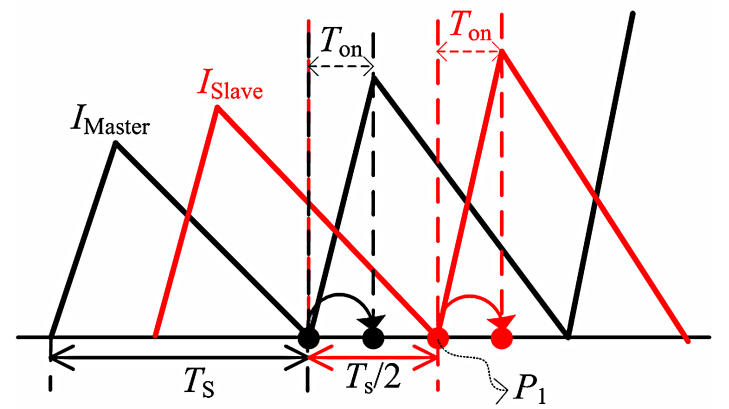

Fig. 2. Shifting turn-on signal to achieve interleaving operation.

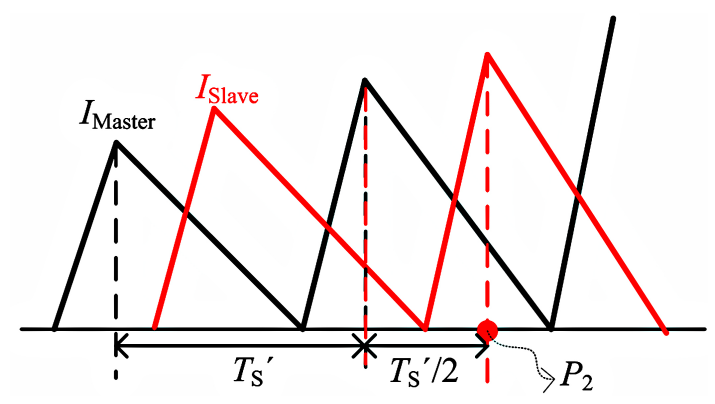

Fig. 3. Shifting turn-off signal to achieve interleaving operation.

\section{B. Type II Phase shift method}

As shown in Fig. 3the slave phase is turned on by a zero current detector signal but turned off by shifting the turnoff signal P2, which is generated from the master phase and always lagging the master phase by $180^{\circ}$.

With this phase-shift method, both the master phase and the slave phase can work in CRM mode.

For an interleaved CRM boost converter, $P_{2}$ is a better choice for a converter in the slave stage, since it requires a zero voltage detector to generate a turn-on signal and can insure the soft-switching feature. As for $P_{1}$, the slave stage may not turn on with soft-switching.

However, when using the type II phase shift method to achieve interleaving operation, the inductor current of the slave phase exhibits a sub-harmonic oscillation phenomenon at high line voltage. The turning-on time of the slave phase is not equal to the master phase anymore. Both the simulation and experimental results proved it, as shown in Fig. 4.

\section{PERFORMANCE ANALYSIS}

An ideal instance of the type II phase-shift control scheme is when the turning-on period of the slave phase is equal to the master phase. However, if a disturbance at the input voltage or the output voltage occurs, then there will be a $\Delta T_{\text {on }}$ between the actual and ideal turning on period. The inductor current waveforms are illustrated in Fig. 5. $I_{\text {Master }}$ is the master phase inductor current waveform, $I_{\text {Slave }}$ is the ideal slave phase inductor current waveform and $I_{\text {Slave }}^{\prime}$ is the actual slave phase inductor current waveform after a disturbance $\Delta T_{o n}$. Fig. 5(a) and Fig. 5(b) are two different instances after a disturbance. In Fig. 5(a), the slave inductor current begins oscillation and is unstable. In Fig. 5(b), the slave inductor is gradually becoming stable. 
If the slave current $I_{\text {Slave }}^{\prime}$ is stable, $\Delta T_{\text {on }}$ should be convergent, as shown in Fig. 5(b). When the switches are turning on, the inductor currents are increasing at the same rate. When the switches are turning off, the inductor currents are decreasing at the same rate. The rising and falling slope of the inductor current can be calculated form Fig. 5:

$$
\begin{aligned}
S_{n} & =\frac{U_{i n}}{L} \\
S_{f} & =\frac{U_{i n}-U_{o}}{L} .
\end{aligned}
$$

So we can get

$$
\left|\frac{\Delta T_{o n}{ }^{\prime}}{\Delta T_{o n}}\right|=\frac{U_{i n}}{U_{o}-U_{i n}}<1
$$

Then

$$
U_{\text {in }}<\frac{1}{2} U_{o} .
$$

This relationship can also be derived according to the magnetic flux balance of the boost inductors:

$$
\begin{aligned}
& \frac{U_{o}}{U_{i n}}=\frac{2}{1-D} \\
& D=1-\frac{2 U_{i n}}{U_{0}} .
\end{aligned}
$$

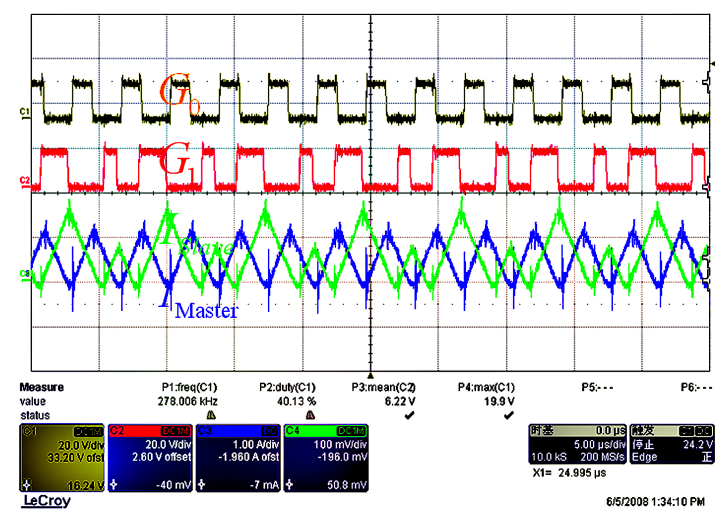

(a) Experimental waveforms of inductor currents $I_{\text {Master }}$ and $I_{\text {Slave }}$, and gate signals $G_{0}$ and $G_{1}$

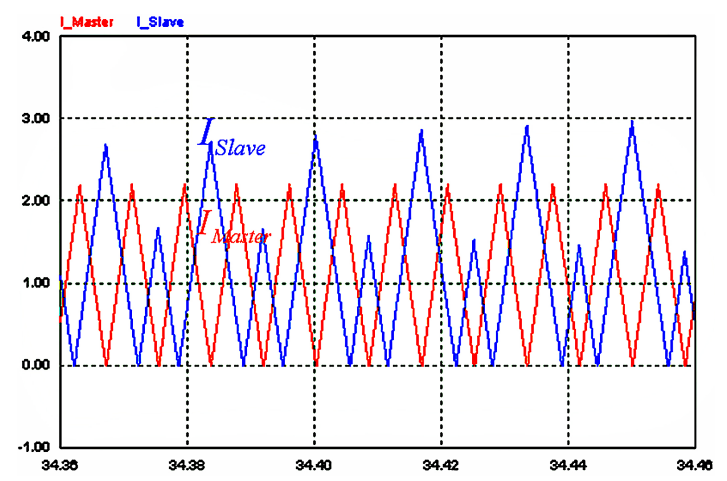

(b) Simulation waveforms of inductor currents $I_{\text {Master }}$ and ISlave

Fig. 4. Sub-harmonic oscillation phenomenon.

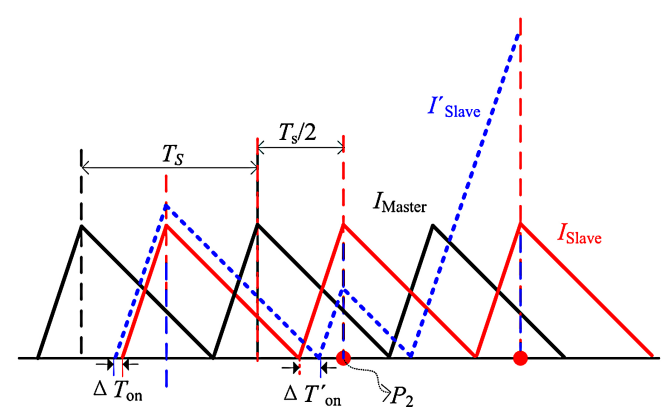

(a) $D<0.5$

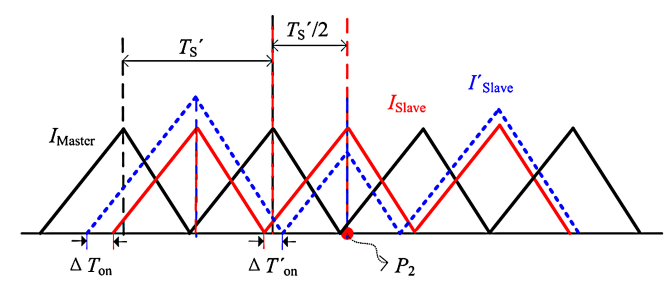

(b) $D>0.5$

Fig. 5. The inductor currents after a disturbance $\Delta T_{\text {on }}$.

Because $D \leq 1$, hence

$$
U_{0} \geq \frac{1}{2} U_{\text {in }} .
$$

This equation shows that the output voltage should be at least two times the input voltage. So if the type II phase shift method is adopted, a sub-harmonic oscillation is unavoidable when $U_{i n}>0.5 U_{o}$, as it is shown in Fig. 5(a).

In this paper, a simple control scheme is proposed for a twophase boost converter. The theory behind this control method and its operation modes will be explained below.

\section{PROPOSED PHASE-SHIFT INTERLEAVING CONTROL SCHEME}

In order to solve this problem and utilize the advantages of the shifting turn-off signal method, this paper gives a complete analysis of the sub-harmonic oscillation phenomena in section III. Moreover, a novel phase-shift interleaving control scheme is proposed.

In peak current mode control, we adopt ramp compensation to keep the current stable and to avoid sub-harmonic oscillation. Actually, ramp compensation sacrifices the power factor to achieve a stable current. Similarly we can change the interleaving method to keep $\Delta T_{\text {on }}$ convergent.

From the previous analysis, we can see that ZVS, the $180^{\circ}$ phase shift and stability can not all be obtained in one design. Since ZVS is the main feature of this method, so in order to achieve stability, the $180^{\circ}$ phase shift should be sacrificed. To illustrate the operation process, the main waveforms are shown in Fig. 6 and Fig. 7, respectively.

When the type I phase shift method is adopted, just as the $I_{\text {Slave }}^{\prime}$, the turning-on period of the slave phase after a disturbance is:

$$
T_{\text {on_slave }}=\Delta T_{o n}+T_{o n} .
$$




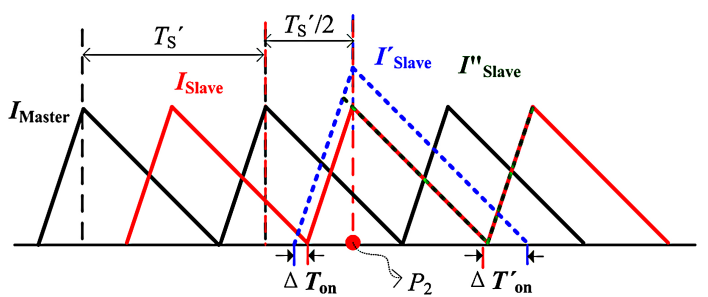

Fig. 6. Waveforms of $I_{\text {Master }}, I_{\text {Slave }}, I_{\text {Slave }}^{\prime}$ and $I_{\text {Slave }}^{\prime \prime}$.

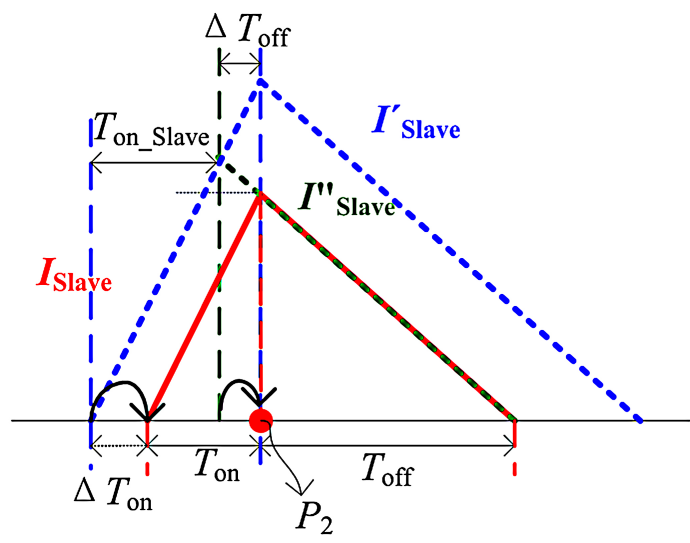

Fig. 7. Waveforms of $I_{\text {Slave }}, I_{\text {Slave }}^{\prime}$ and $I_{\text {Slave }}^{\prime \prime}$

The disturbance after a switching cycle is

$$
\left|\Delta T_{o n}{ }^{\prime}\right|=\frac{U_{i n}}{U_{o}-U_{i n}}\left|\Delta T_{o n}\right| .
$$

If we want to keep $\Delta T_{o n}{ }^{\prime}=0$, just like the $I_{\text {Slave }}^{\prime \prime}$, as shown in Fig. 6, then the turning-on period of the slave phase is

$T_{o n \_s l a v e}=T_{o n \_m a s t e r}+\Delta T_{o n}-\Delta T_{\text {off }}=D \cdot \Delta T_{\text {on }}+T_{\text {on }}(10)$ $D=\frac{T_{\text {on }}}{T_{\text {on }}+T_{\text {off }}}$.

We assume that the difference between the two adjacent operation periods can be omitted. As a result, we can make use of the previous duty cycle to determine the present duty cycle.

Therefore, we can keep $\Delta T_{\text {on }}$ convergent by controlling $\Delta T_{\text {on_slave. }}$ By using the proposed phase-shift control scheme, both the master and the slave phase can work in CRM mode and the phase-shift is nearly $180^{\circ}$.

Similarly, we can get a coefficient k, as shown in Fig. 8 by

$$
T_{\text {on_slave }}=k \cdot \Delta T_{\text {on }}+T_{\text {on_master }} .
$$

When $k<0, \frac{\Delta T_{o n}{ }^{\prime}}{\Delta T_{o n}}<-1$, like $I_{\text {Slave } 1}$;

When $k=0, \frac{\Delta T_{o n}^{\prime}}{\Delta T_{o n}}=-1$, like $I_{\text {Slave } 2}$;

When $k=D=\frac{T_{o n}}{T_{o n}+T_{o f f}}, \frac{\Delta T_{o n}{ }^{\prime}}{\Delta T_{o n}}=0$, like $I_{\text {Slave } 3}$;

When $k=2 D=\frac{2 T_{o n}}{T_{o n}+T_{o f f}}, \frac{\Delta T_{o n}{ }^{\prime}}{\Delta T_{o n}}=1$, like $I_{\text {Slave }}$;

When $k>2 D, \frac{\Delta T_{o n}{ }^{\prime}}{T_{o n}}>1$, like $I_{\text {Slave } 5}$;

So, we can see

when $0<k<2 D,\left|\frac{\Delta T_{o n}{ }^{\prime}}{\Delta T_{o n}}\right|<1$.

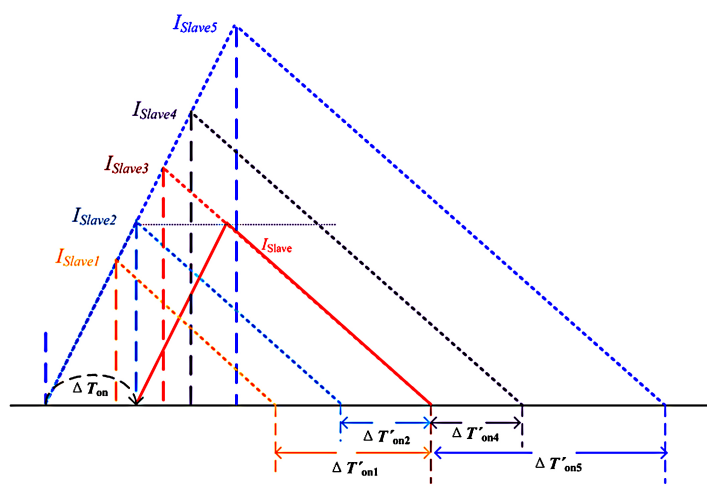

Fig. 8. Slave inductor current waveforms with different coefficient $k$.

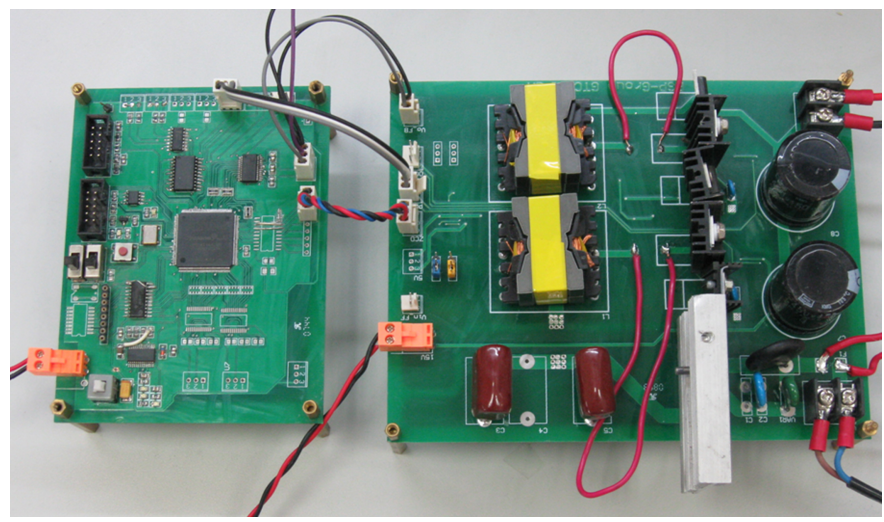

Fig. 9. Photo of the experimental setup.

In addition, we can use the PI or PID method to keep $\Delta T_{\text {on }}$ convergent. Experiments have proved that this interleaving method is feasible. The slave phase works in CRM mode and $\Delta T_{o n}$ is almost zero.

\section{EXPERIMENTAL RESULTS}

In order to verify the feasibility of the proposed interleaving phase-shift control scheme, an experimental two phase interleaved boost PFC converter was designed and built. The digital controller was implemented using FPGA and AD converters. The control algorithm was developed using a hardware description language (Verilog HDL). The following specifications were implemented:

- No. of phases: $2\left(180^{\circ}\right.$ phase shift $)$

- Operating frequency: $35 \mathrm{kHz} 450 \mathrm{kHz}$

- Input voltage: $V_{i n}=85 \sim 265 V_{\text {rms }}$

- Output voltage: $V_{\text {out }}=400 V_{d c}$

- Total output power: $P_{o}=250 \mathrm{~W}$ (2-phase)

- Output capacitor: $C_{d c}=300 \mu \mathrm{F}$

The experimental setup of a CRM Boost PFC with the novel phase-shift control scheme is shown in Fig. 9.

Fig. 10 shows the gate signals $G_{0}$ and $G_{1}$, and the $I_{\text {Slave }}$ when the duty cycle $D>0.5$. It can be seen that the slave phase inductor current $I_{\text {Slave }}$ works in CRM mode. The rising edge of $G_{2}$ shows the ideal turning-on moment of the slave phase. $\Delta T_{o n}$ is the difference of the rising edge between $G_{1}$ and $G_{2}$. Since $\Delta T_{o n}$ is very small, the phase shift is almost $180^{\circ}$. 


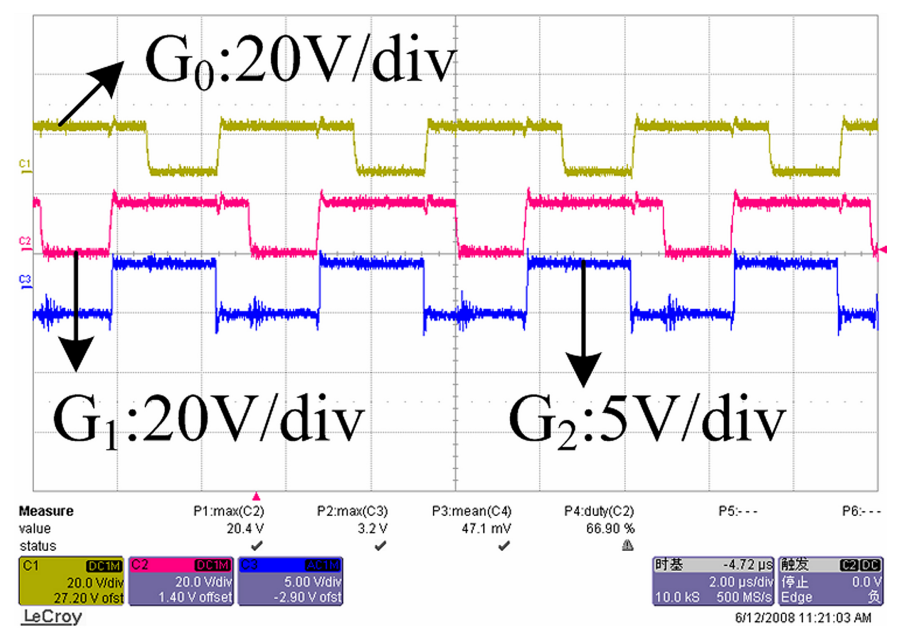

(a) $\left(G_{0}, G_{1}: 20 \mathrm{~V} / \mathrm{div}, G_{2}: 5 \mathrm{~V} / \mathrm{div} ; 2.00 \mu \mathrm{s} / \mathrm{div}\right)$

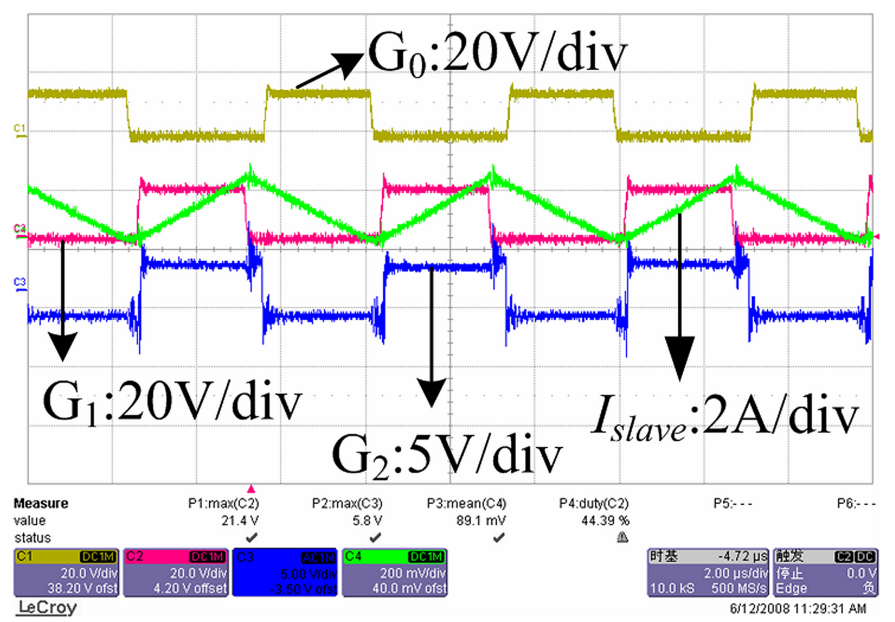

(b) (I $I_{\text {Slave }}: 2 \mathrm{~A} /$ div $, G_{0}, G_{1}: 20 \mathrm{~V} /$ div $, G_{2}: 5 \mathrm{~V} /$ div $; 2.00 \mu \mathrm{s} /$ div $)$

Fig. 10. Gate signal when $D>0.5$. (a) Measured gate signals $G_{0}$ and $G_{1}$ and the ideal turning-on waveforms $G_{2}$; (b) Measured inductor current

$I_{\text {Slave }}$ and gate signals $G_{0}$ and $G_{1}$ and the ideal turning-on waveforms $G_{2}$.

Fig. 11 shows the inductor currents $I_{\text {Master }}$ and $I_{\text {Slave }}$, and $G_{0}$ and $G_{1}$ of the interleaved boost PFC. It can be observed that both the master phase and the slave phase are working in CRM mode.

Fig. 12 shows the input voltage $V_{i n}$, the input current $I_{\text {in }}$ and the output voltage $V_{O}$ of the PFC while $P_{o}=250 \mathrm{~W}$. This experimental result is mainly used to demonstrate two things. First, it shows that the proposed control scheme can be used well in a PFC with a full designed load. Second, and most importantly, it can be seen from the output voltage curve that the PFC circuit worked very well without any sub-harmonic oscillation. If this system was an unstable one, there would be some noise on the output voltage curve. There would not be a smooth curve as shown in Fig. 12.

\section{CONCLUSIONS}

This paper described a quantitative analysis of the subharmonic oscillation phenomena when adopting turnoff time shifting control schemes for interleaved boost converters operating in critical conduction mode. Based on that, a novel modified turnoff time shifting control scheme was proposed

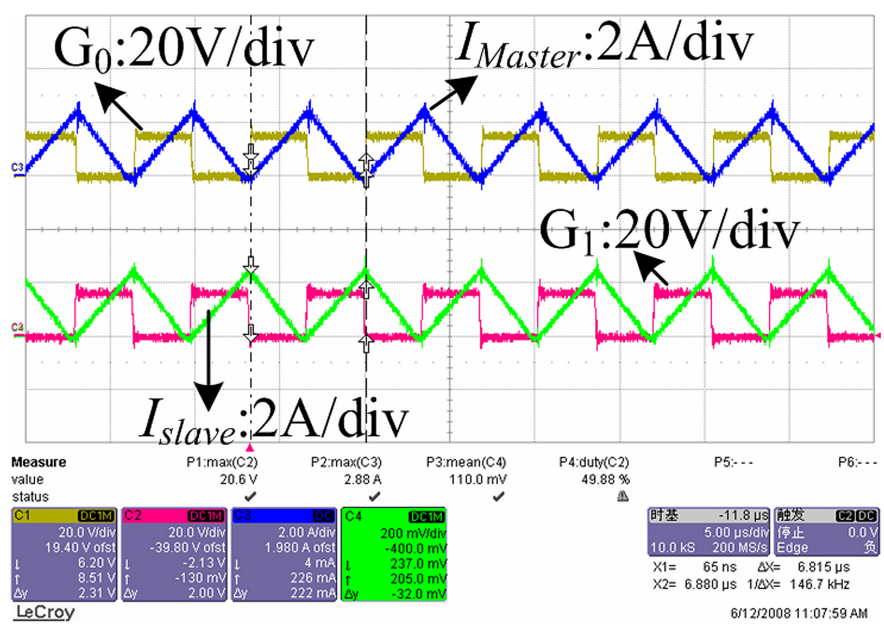

(a) $\left(I_{\text {Master }}, I_{\text {Slave }}: 2 \mathrm{~A} /\right.$ div $, G_{0}, G_{1}: 20 \mathrm{~V} /$ div $; 5.00 \mu \mathrm{s} /$ div $)$

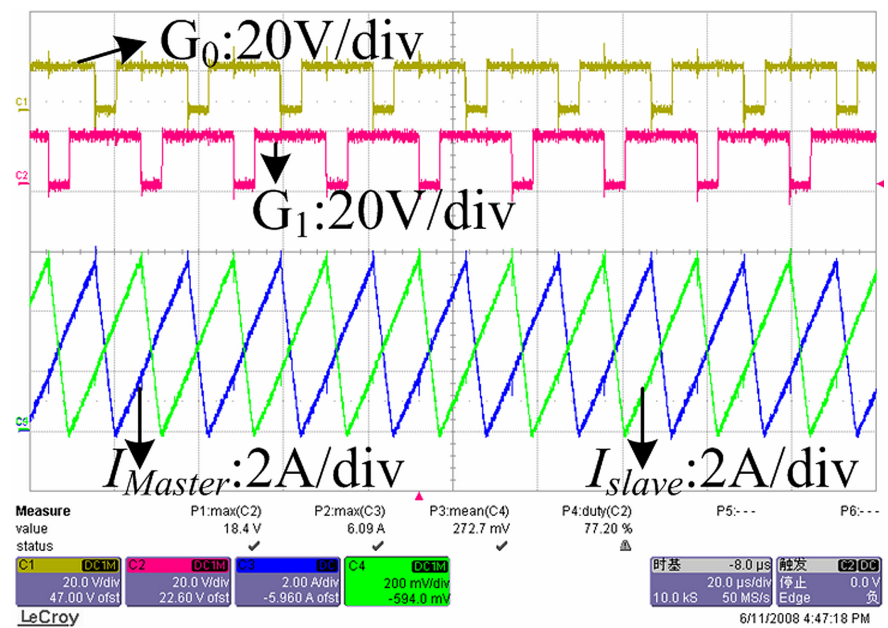

(b) $\left(I_{\text {Master }}, I_{\text {Slave }}: 2 \mathrm{~A} / \mathrm{div}, G_{0}, G_{1}: 20 \mathrm{~V} / \mathrm{div} ; 5.00 \mu \mathrm{s} / \mathrm{div}\right)$

Fig. 11. Inductor currents of the interleaved boost PFC. (a) Measured inductor current $I_{\text {Master }}, I_{\text {Slave }}$ and gate signals $G_{0}, G_{1}$ and the ideal turning-on waveforms $G_{2}$. (b) Measured inductor current $I_{\text {Master }}, I_{\text {Slave }}$ and gate signals $G_{0}, G_{1}$.

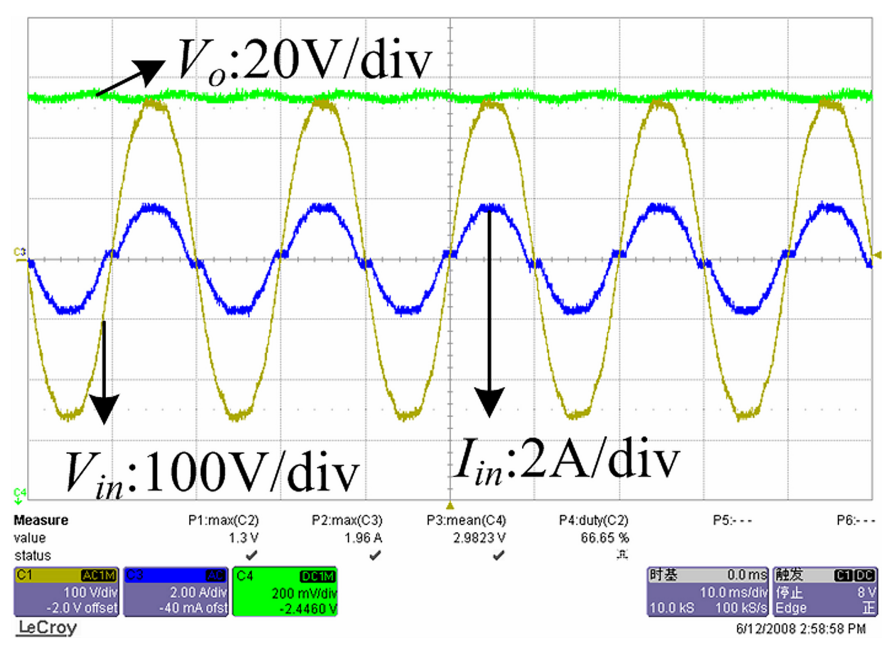

Fig. 12. Measured input voltage $V_{i n}$, input current $I_{i n}$ and output voltage $V_{O}\left(V_{O}: 20 \mathrm{~V} /\right.$ div $, V_{\text {in }}: 100 \mathrm{~V} /$ div $, I_{\text {in }}: 2 \mathrm{~A} /$ div $; 10 \mathrm{~ms} /$ div $)$.

to achieve interleaving operation, where both the master phase and the slave phase can operate stably under CRM mode 
within the full input voltage range. This phase-shift control scheme can be used in other interleaved CRM converters such as the flyback or buck topologies. It can also be extended to more phases.

\section{ACKNOWLEDGMENT}

This work was supported by the National Natural Science Foundation of China (NSFC) under Project 50677054.

\section{REFERENCES}

[1] Han-Ju Cha et. al., "Comparison of PWM strategies for three-phase current-fed DC/DC converters," Journal of Power Electronics, Vol. 8, No. 4, pp. 363-370, Oct. 2008.

[2] G. Spiazzi, D. Tagliavia, and S. Spampinato, "DC-DC flyback converters in the critical conduction mode: A re-examination," in Proc. Ind. Appl. Conf., Vol. 4, pp. 2426-2432, 2000.

[3] Y. V. Panov, F. C. Lee, and J. G. Cho, "A new three-phase AC-DC zerovoltage-switching isolated converter operating in DCM," in Proc. Ind. Appl. Conf., Vol. 3, pp. 2602-2609, 1995.

[4] J. E. Baggio, H.L. Hey, H.A. Grundling, H. Pinheiro, J.R. Pinheiro, "Isolated interleaved phase shift PWM DC-DC ZVS converter," IEEE Transactions on Industry Applications, Vol. 39, No. 4, pp.1795-1802, Nov./Dec. 2003.

[5] R. Giral, L. Martinez-Salamero, and S. Singer, "Interleaved converters operation based on CMC," IEEE Transactions on Power Electronics, Vol. 14, No. 4, pp. 643-652, Jul. 1999.

[6] M. T. Zhang, M. M. Jovanovic, and F. C. Lee, "Analysis and evaluation of interleaving techniques in forward converters," IEEE Transactions on Power Electronics, Vol.13, No. 4, pp. 690-698, Jul. 1998.

[7] Kang-Hyun Yi et. al., "A novel two phase interleaved LLC series resonant converter using a phase of the resonant capacitor," Journal of Power Electronics, Vol. 8, No. 3, pp. 275-279, Oct. 2008.

[8] C. M. de Oliveira Stein et. al., "A ZCT auxiliary commutation circuit for interleaved boost converters operating in critical conduction mode," IEEE Trans. Power Electron., Vol. 17, No. 6, pp. 954-962, Nov. 2002.
[9] C. Sudhakarababu et. al., "DSP based control of interleaved boost converter," Journal of Power Electronics, Vol. 5, No. 3, pp. 180-189, Oct. 2005.

[10] Mummadi Veerachary, "Performance improvement of voltage-mode controlled interleaved buck converters," Journal of Power Electronics, Vol. 5, No. 2, pp. 104-108, Jun. 2005.

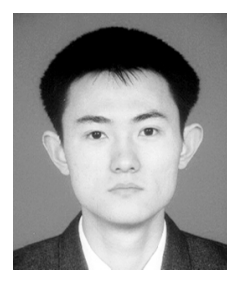

Xu Yang was born in China in 1972. He received his B.S. and Ph.D. in Electrical Engineering from Xi'an Jiaotong University, Xi'an, China, in 1994 and 1999, respectively. He has been a member of the faculty of the School of Electrical Engineering, Xi'an Jiaotong University since 1999, where he is presently a Professor. From November 2004 to November 2005, he was with the Center of Power Electronics Systems (CPES), Virginia Polytechnic Institute and State University, Blacksburg, VA, as a Visiting Scholar. He then came back to Xi'an Jiaotong University, and began teaching and doing research in the areas of power electronics and industrial automation. His current research interests include soft switching topologies, PWM control techniques, power electronic integration, and packaging technologies.

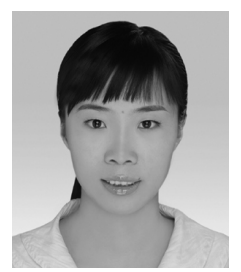

Yanping Ying was born in Nanjing, China, in 1985 She received her B.S. and M.S. in Power Electronics from Xi'an Jiaotong University, China, in 2006 and 2009, respectively. She is currently working at the China South Locomotive \& Rolling Stock Corp. Ltd. in Nanjing China. Her current research interests include $\mathrm{dc} / \mathrm{dc}$ converters, digital control, and switched mode power supplies.

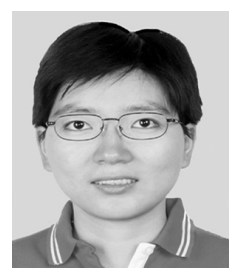

Wenjie Chen was born in Xi'an, China, in 1974. She received her B.S., M.S. and Ph.D. in Electrical Engineering from Xi'an Jiaotong University, Xi'an, China, in 1996, 2002 and 2006, respectively. She has been a member of the faculty of the School of Electrical Engineering, Xi'an Jiaotong University since 2002, where she is currently an Associate Professor. Her main research interests include soft-switching dc/dc converters and active filters, and power electronic integration. 